\title{
BMJ Open Quality What drives general practitioners in the UK to improve the quality of care? A systematic literature review
}

\author{
Kanwal Ahmed (D) , ${ }^{1}$ Salma Hashim, ${ }^{1}$ Mariyam Khankhara, ${ }^{1}$ Ilhan Said (D) , ${ }^{1}$ \\ Amrita Tara Shandakumar, ${ }^{2}$ Sadia Zaman, ${ }^{1}$ Andre Veiga ${ }^{3}$
}

To cite: Ahmed K, Hashim S, Khankhara M, et al. What drives general practitioners in the UK to improve the quality of care? A systematic literature review. BMJ Open Quality 2021;10:e001127. doi:10.1136/ bmjoq-2020-001127

Received 26 July 2020 Revised 22 December 2020 Accepted 21 January 2021
Check for updates

(c) Author(s) (or their employer(s)) 2021. Re-use permitted under CC BY-NC. No commercial re-use. See rights and permissions. Published by BMJ.

${ }^{1}$ School of Medicine, Imperial College London, London, UK ${ }^{2}$ School of Medicine, University of Liverpool, Liverpool, UK ${ }^{3}$ Business School, Imperial College London, London, UK

Correspondence to

Miss Ilhan Said;

is2015@ic.ac.uk

\section{ABSTRACT}

Background In the UK, the National Health Service has various incentivisation schemes in place to improve the provision of high-quality care. The Quality Outcomes Framework (QOF) and other Pay for Performance (P4P) schemes are incentive frameworks that focus on meeting predetermined clinical outcomes. However, the ability of these schemes to meet their aims is debated.

Objectives (1) To explore current incentive schemes available in general practice in the UK, their impact and effectiveness in improving quality of care and (2) To identify other types of incentives discussed in the literature.

Methods This systematic literature review was conducted using the Preferred Reporting Items for Systematic Reviews and Meta-Analyses guidelines. Six databases were searched: Cochrane, PubMed, National Institute for Health and Care Excellence Evidence, Health Management Information Consortium, Embase and Health Management. Articles were screened according to the selection criteria, evaluated against critical appraisal checklists and categorised into themes.

Results 35 articles were included from an initial search result of 22087. Articles were categorised into the following three overarching themes: financial incentives, non-financial incentives and competition.

Discussion The majority of the literature focused on QOF. Its positive effects included reduced mortality rates, better data recording and improved sociodemographic inequalities. However, limitations involved decreased quality of care in non-incentivised activities, poor patient experiences due to tick-box exercises and increased pressure to meet non-specific targets. Findings surrounding competition were mixed, with limited evidence found on the use of non-financial incentives in primary care.

Conclusion Current research looks extensively into financial incentives, however, we propose more research into the effects of intrinsic motivation alongside existing $\mathrm{P} 4 \mathrm{P}$ schemes to enhance motivation and improve quality of care.

\section{INTRODUCTION}

WHO defines quality of care as the extent to which healthcare services provided to individuals and patient populations improve desired health outcomes. In order to achieve this, healthcare must be safe, effective, timely, efficient, equitable and people centred.' However, the subjective nature of 'quality' has made measuring and improving care difficult.

Primary care within the National Health Service (NHS) in the UK has various incentivisation schemes in place to improve the provision of high-quality care. The Quality Outcomes Framework (QOF) and other Pay for Performance (P4P) schemes are financial incentive frameworks that focus on meeting predetermined clinical outcomes.

QOF was introduced in April 2004 as part of wider contract reforms in general practice and is one of the $\mathrm{P} 4 \mathrm{P}$ schemes globally. QOF's key aims were to reduce the quality gap between practices, increase primary care funding and improve staff recruitment. ${ }^{2}$

While QOF is voluntary, over $95 \%$ of practices participate. ${ }^{3}$ Points are awarded for achieving outcomes based on National Institute for Health and Care Excellence (NICE) evidence-based indicators, with a monetary reward per point. ${ }^{4} \mathrm{~A}$ total of ' 559 points are available across 77 indicators; with each worth an average of $£ 179.26$ in $2018 / 2019$ '. In England, most practices receive between $10 \%$ and $15 \%$ of practice income from the scheme. ${ }^{2}$

In addition to financial incentive schemes, economists cite competition as being essential to driving improved standards and efficiency. Competition was first established in the NHS in 1991 with the formation of the internal market and today, the NHS operates in a quasi-market. ${ }^{5}$ For example, patients can choose to change practice, directly impacting the practice register and consequently practice's capitation payment. Practices can also bid for local services which are directly commissioned by CCGs for the delivery of care for a condition, for example, dementia. ${ }^{6}$

However, the ability of these methods to incentivise general practitioners (GPs) and improve the quality of care is debated. ${ }^{3}$ This 


\section{Table 1 Search terms for the SLR}

\begin{tabular}{ll}
\hline Search terms & Enticement \\
& Motivation \\
Incentives & Reward \\
& Enticement \\
& Motivation \\
General practice & Incentives \\
& Reward \\
Enticement & Motivation \\
Primary care & Incentives \\
& Reward \\
\hline
\end{tabular}

GP, general practitioner; SLR, systematic literature review.

systematic literature review (SLR) conducted an in-depth analysis into the available literature surrounding this topic, aggregated the findings and discussed the overarching arguments and evidence.

\section{OBJECTIVES}

1. To explore current incentive schemes available in general practice in the UK, their impact and effectiveness in improving quality of care.

2. To identify other types of incentives discussed in the literature.

\section{METHODS}

This SLR was conducted to investigate the proposed research question using the Preferred Reporting Items for Systematic Reviews and Meta-Analyses guidelines. The following six databases were searched: Cochrane, PubMed, NICE Evidence, Health Management Information Consortium, Embase and Health Management.

The search terms in table 1 were generated by identifying relevant synonyms for the term 'incentives' and selecting commonly used tags in literature, which were then finalised after review by the six researchers.

Articles were screened according to the selection criteria in table 2 by all members of the research team. Two rounds of inclusion and exclusion criteria were applied to select papers: the first round to titles and

\begin{tabular}{|c|c|}
\hline Inclusion criteria & Exclusion criteria \\
\hline $\begin{array}{l}\text { Timeframe between } 2009 \text { and } \\
2019\end{array}$ & Disease specific \\
\hline $\begin{array}{l}\text { Study includes the UK or } \\
\text { England }\end{array}$ & No UK studies included \\
\hline Articles & Non-healthcare related \\
\hline English language & Opinion articles \\
\hline
\end{tabular}

abstracts with removal of duplicates and the second round after examining full texts. These articles were then snowballed to ensure extensive coverage of grey literature. Any ambiguous papers were reviewed by two independent researchers. Selected articles after the screening stages were then summarised independently by researchers into a standardised reporting template which were then categorised into themes.

\section{Quality assessment}

Articles were evaluated against the Mixed Methods Appraisal tool, A Measurement Tool to Assess Systematic Reviews, a Generic Appraisal Tool for Epidemiology and Critical Appraisal Skills Programme checklists according to their study type.

\section{Justification of selection criteria}

Initial scope for our search included: articles to widen understanding, studies conducted in the UK, available in full text and published from 2009. This provides a 10-year domain and offers a time-horizon wide enough to allow effects of policy changes to be measured. Only UK-based studies were included to substantiate relevance to the NHS specifically, though disease-specific results were excluded due to their lack of generalisability.

\section{RESULTS}

Of the 35 studies included in this review (figure 1), 29 were exclusive to the UK and the remaining bincluded data from other countries as well as the UK. ${ }^{7-12}$

\section{DISCUSSION}

The findings from this SLR (figure 2) are summarised as follows:

\section{Financial methods for incentivising care \\ The impact of P4P schemes}

$\mathrm{P} 4 \mathrm{P}$ schemes were introduced in the NHS as financial incentives for healthcare providers to improve quality care, motivating them to increase standards. QOF is one of the largest, most-well known P4P schemes.

Financial incentives can be classified under different categories, due to different payment systems in healthcare. An international systematic review of payment methods by Flodgren et al, found capitation, fee-forservice and target payment as the most effective methods to motivate healthcare professionals (HCPs), improving $48 / 69,7 / 10$ and $17 / 20$ outcome measures respectively. ${ }^{7}$ Although these payment methods were found to motivate GPs, they were limited in their effect in improving patient outcomes overall. However, this study evaluates different HCPs including dentists and nurses, so generalisability to GPs is limited.

Peckham and Gousia conducted a literature review which argued that fee-for-service instigated supplier induced demand. ${ }^{8}$ This resulted in over provision of treatments by doctors, causing overconsumption of 

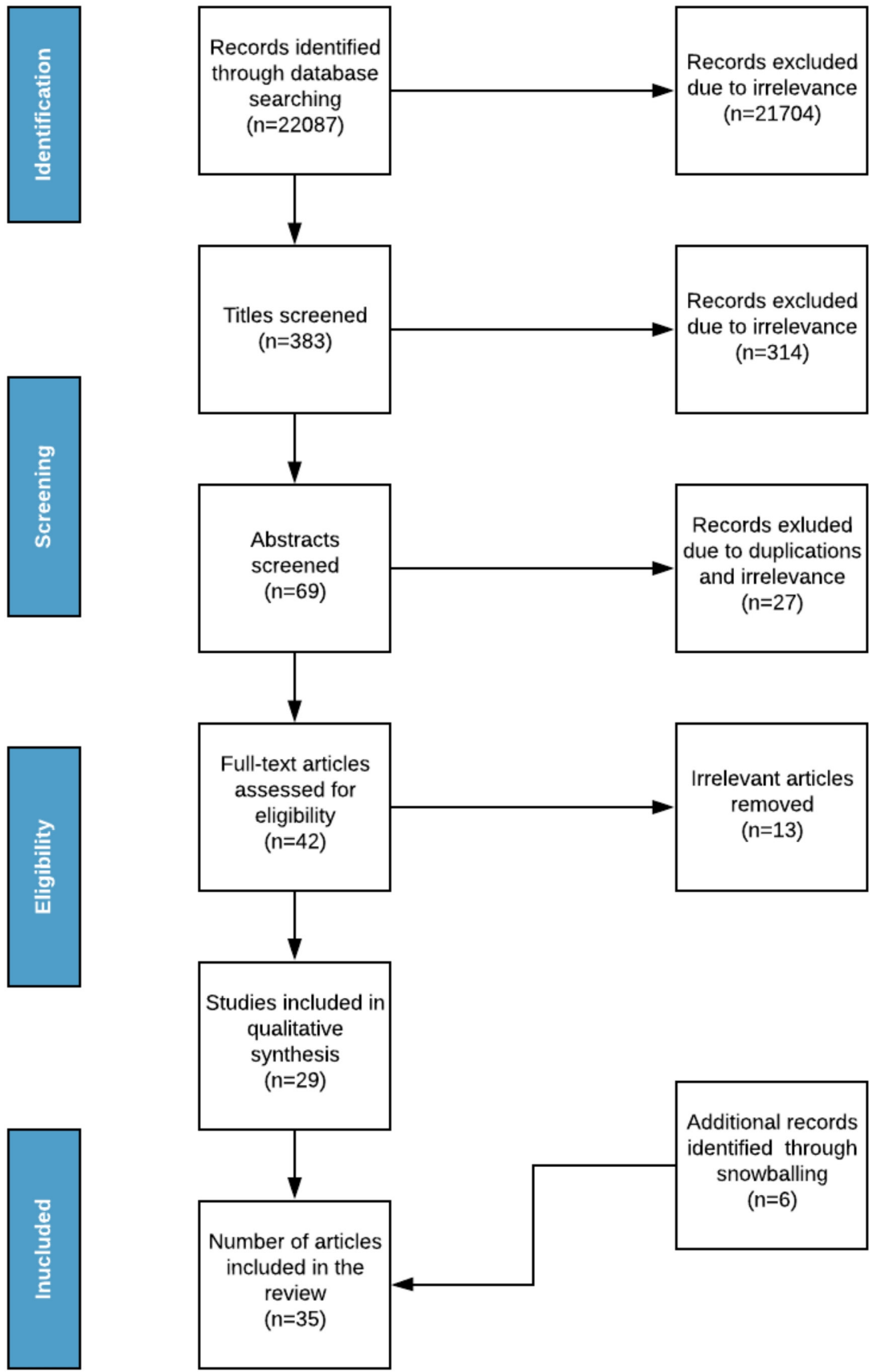

Figure 1 PRISMA flow diagram. PRISMA, Preferred Reporting Items for Systematic Reviews and Meta-Analyses.

unnecessary treatments by patients. However, this potentially unloads the burden from secondary care as GPs reduce referrals to specialists, opting to do more themselves. Capitation and salary-based payment methods were found to lower both activity and effort from physicians, and instigate 'cream-skimming' patients. This is where practices predominantly take on healthy patients who require fewer resources and are therefore cheaper to manage. In practicality, a combination of payment models are used to pay GPs. However, evaluating each payment method individually is still beneficial as it determines the most favourable and most effective combination. This review, however, has limited relevance as only 1 of the 38 studies was conducted in the UK. Primary care in the UK uses a restricted supply model and open patient registration with little interpractice patient transfer which limits the impact of financial payment systems compared with other countries.

Alongside financial incentives from QOF, there are reputational incentives. These are perceptions of the provider from competitors and the public using published performance data. Evidence from an observational study including 8929 practices carried out by Allen et al showed providers are more sensitive to reputational incentives of QOF scores than financial, resulting in increased performance and longer effectiveness. ${ }^{13}$ However, difficulty measuring reputational incentives could affect the accuracy of the results.

In conclusion, $\mathrm{P} 4 \mathrm{P}$ schemes have been found to have mixed effects. They have been shown to increase the 


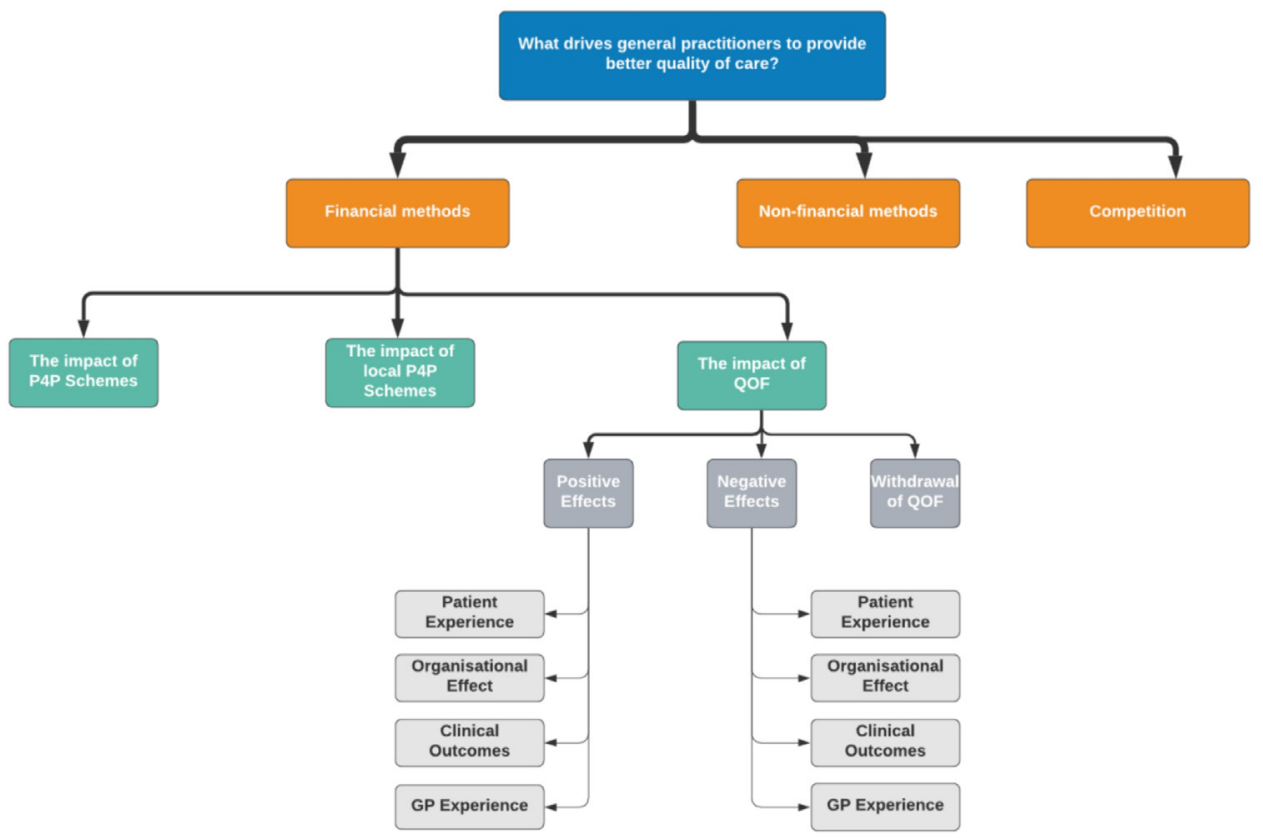

Figure 2 Summary of findings. GP, general practitioner; P4P, Pay for Performance; QOF, Quality Outcomes Framework.

number of services available and effectively motivate GPs, however, there are limited data on the direct effects on patient outcomes. ${ }^{78}$ Moving forward, current and future P4P schemes could be evaluated using a performancebased finance framework. ${ }^{9}$ This framework is split into five domains: the environment prior to implementation, the ability of the P4P scheme to meet local needs, the use of appropriate performance criteria, implementation and the effects of the scheme. This can be applied to any $\mathrm{P} 4 \mathrm{P}$ scheme and can be used to identify key issues and set future targets.

\section{The impact of local P4P schemes}

A study by Hackkett $e t$ al was conducted in socioeconomically deprived areas. ${ }^{14}$ It elicited four key themes related to local P4P schemes: ownership, credibility of the indicators, influences on behaviour, and exacerbated tensions. Ownership was mentioned by primary care professionals as the measure of relevance of targets to the local population. Results found local targets to be similarly tailored to the needs of the local population compared with national ones. Credibility of the local indicators was deemed to be high as they were evidence based. However, there were doubts surrounding indicators focusing on health promotion which required patient action, for example, alcohol or weight loss. The study also highlighted that GPs in lower socioeconomic areas were motivated by financial incentives whereas those in higher socioeconomic areas were motivated by patient benefit, an intrinsic motivator. This study shed light on the effectiveness of local schemes, however, the influences of social desirability bias may have reduced the reliability of these accounts. Participants were also under-represented in poorer performing practices due to lower participant involvement so this may be unrepresentative and of limited relevance nationally.
The impact of QOF

The many reforms QOF has undergone since its introduction paves way for a lot of scrutiny from practitioners and commissioners alike. While some studies report distinct positive and negative effects of the scheme on general practice, many remain unclear regarding its effects.

A study conducted by Roland and Campbell gave an overview of the different clinical indicators created by QOF, using 20 systematic reviews. ${ }^{15}$ The indicators were split into three domains: clinical, organisational and patient experience, taken from clinician and patient perspectives. This SLR follows a similar format.

\section{Positive effects of QOF}

\section{Patient experience}

Patient satisfaction as a measure of quality of care was observed in the study conducted by Raleigh and Frosini which identified that practices with higher patient satisfaction tended to have higher QOF scores, particularly in terms of accessibility. ${ }^{16}$ QOF has been shown by this study to improve patient experience in some areas. This paper analysed data from 8042 practices which increases its reliability however, the sample may still be biased. The researchers identified a 'London effect' in that Londoners respond more negatively across all NHS surveys, suggesting a more skewed view on quality of care, reflecting the unique challenges of diversity, infrastructure, smaller practices and urban lifestyles.

\section{The effects of QOF on clinical outcomes}

Efficiency in QOF can be measured by the number of hospital admissions avoided, healthcare prevention or mortality rates. Fleetcroft $e t$ al conducted a cross-sectional study which observed a decrease in mortality rates when QOF was introduced in 2004. ${ }^{17}$ The results showed 
evidence of reduced mortality for 25 out of 80 indicators, saving approximately 11/100 000 lives a year, that is, 6600 additional lives saved. However, the study found that the estimated maximum effect was not reached, particularly after the 2006 changes. This may be due to practices not being incentivised to reach $100 \%$ for remuneration. A limitation of this study was the use of 80 indicators, which puts it at risk of 'multiple hypothesis testing' due to a higher chance of accidental discovery from multiple inaccurate inferences being made. Furthermore, with trends showing improvement prior to the introduction of QOF, it is difficult to ascertain whether QOF alone was responsible for reducing mortality. Kontopantelis et al refute the findings from Fleetcroft $e t a l$ and conclude no associated immediate reduction in premature mortality rates. Instead, they suggest that QOF could be associated with a reduction in morbidity incidence and improved quality of life, which may allow for long-term mortality reductions. ${ }^{18}$

Fleetcroft $e$ al showed that quality-adjusted life years were gained for 28 indicators, resulting in an estimated 22 additional deaths prevented in 1 year for an average sized practice. ${ }^{19}$ Another study also provided evidence in support of specific indicators of QOF such as primary prevention for hypertension and influenza immunisation. ${ }^{17}$

Doran et al measured quality of care by the achievement rates of practices in a longitudinal analysis. ${ }^{20} \mathrm{It}$ compared the predicted and actual rates, and found a $37.7 \%$ increase in achievement across 42 indicators. QOF was shown to have a positive association between changes to care and greater achievement in incentivised activities.

A systematic review by Mandavia et al analysed 28 papers on the use of $\mathrm{P} 4 \mathrm{P}$ in the NHS. ${ }^{21} \mathrm{QOF}$ had mixed results with some conditions seeing improved outcomes over others. Several studies agree with these findings. ${ }^{1022}$ One example cited initial improvements in clinical outcomes for asthma and diabetes but no change in coronary heart disease (CHD). However, there were still discrepancies within the same disease. For instance, it was found that patients with diabetes with comorbidities benefited from QOF while those without comorbidities were negatively impacted. $^{21} 22$

Dixon et al aimed to understand the differences in health inequalities involving statistical modelling and qualitative analysis. ${ }^{23}$ The study concluded that QOF reduced the gap between the least and most deprived practices and was a good incentive for poorly performing practices to improve. Gillam et al quantified the reduction of sociodemographic inequalities from $4 \%$ to $0.8 \% .^{24}$

\section{Organisational effect}

NHS England conducted an in depth analysis of the literature and qualitative interviews with key stakeholders and concluded that QOF supports advancements in the management of long term conditions. ${ }^{3}$ Furthermore, there is a consensus that QOF has improved data recording. ${ }^{2325}$ This can be shown in a review by Mandavia et al where the implementation of QOF had a $19.9 \%$ increase in annual recording rates of 5 health indicators. ${ }^{21}$

\section{GP experience}

A study of over 2000 doctors by Fichera and Pezzino used linear regression models to display the effect of QOF on contractual agreement. ${ }^{26}$ It found that doctors working in better performing practices were less likely to move practice and more 'efficient' doctors were more likely to become partners, up to the age of 35 , after which the probability decreases. However, a major assumption made in the study design was that 'efficiency' in terms of QOF performance was attributed solely to doctors' efforts.

\section{Summary}

In conclusion, key positives identified include decreased health inequalities relating to social deprivation, improved data recording and increased awareness to previously neglected areas. It must be noted that the papers used in this SLR measured the effectiveness of multiple indicators of QOF simultaneously. This is useful in determining the overall effectiveness but also increases likelihood of bias from multiple hypothesis testing.

\section{Negative effects of QOF \\ Patient experience}

Cripps, the NHS director for NHS 'Right care', splits value into three domains. ${ }^{27}$ Allocative value, to distribute assets evenly based on population need. Technical value, health outcomes divided by the cost. Personal value; subdivided into objective value, to improve health outcomes and subjective value, alignment of outcomes with patient values. It can be argued by the studies described in 'Positive effects of QOF' that QOF increases both technical and allocative value as it improves health outcomes. ${ }^{17}$ However, QOF subsequently drives down personal value as patient experience and subjective needs are ignored. Norman et al described this as fragmenting care by putting a price on each activity, causing care to become population-centred and less about the individual. $^{28}$

Another example was found in a longitudinal qualitative study by Chew-Graham et al which looked at the effect of QOF on the consultation style of patients with chronic illnesses. ${ }^{29}$ The results showed that from a total of 34 interviews, consultations focusing on QOF resulted in patient needs and concerns not being met. Roland and Campbell highlighted this reduction in holistic care as an unintended consequence of QOF whereby clinicians were incentivised to focus on measurable aspects of care with less time for unmeasured aspects such as the patient-doctor relationship, thus reducing personal value. ${ }^{15}$ Kramer also argues that QOF assumes its targets align with patient interests which is not always the case, as subjective value and technical value can still differ. ${ }^{30}$

In summary, this misalignment of QOF with patients' interests can be used to argue against its effectiveness. The trade-off between allocative and technical against 
personal value begs the question, 'does QOF produce a health benefit and is the trade-off worthwhile?'

\section{The effects of QOF on clinical outcomes}

A limitation of QOF described by Fleetcroft $e t$ al was that positive changes in performance may be attributed to external factors other than QOF itself. ${ }^{19}$ For example, QOF has been criticised for being a mere extrapolation of pre-existing trends, thus making its impact on clinical outcomes difficult to determine. ${ }^{316} 17$ 20-22 252731

Secondly, QOF outcomes are actually indirect measures of health. ${ }^{22}$ It is difficult to directly measure the control of a condition, making clinical judgement essential. QOF tends to measure non-specific indicators such as blood pressure (BP) as a proxy measure for cardiovascular health. A BP within range may give the illusion of good health, despite the possibility of a patient being symptomatic or at a high risk.

Furthermore, according to Dixon et al, QOF has not encouraged nor is it tailored to primary disease prevention. ${ }^{23}$ It is argued that when devising clinically effective targets that can be both appropriately measured and incentivised, certain obstacles cause a focus on proxy measures which involve mainly recording and prescribing. This paves way for heightened focus on the treatment and secondary prevention of chronic diseases over primary prevention and leads to the marginalisation of conditions that are perhaps harder to measure or quantify clinically. This view is supported by NHS England. ${ }^{3}$

QOF was implemented as part of total quality management (TQM) with the goal to increase the overall standards of care. ${ }^{32}$ Although QOF has been able to fulfil this aim, a key part of TQM is continuous quality improvement and questions remain around the extent to which QOF can further contribute to this. For example, Langdown and Peckham and Ashworth and Kordowicz showed the presence of a ceiling effect once practices had reached high thresholds and achieved maximum remuneration, despite potential for additional quality improvement. ${ }^{22} 25$

\section{Organisational effect}

'Exception reporting' is used to exempt patients from individual indicators for various reasons, for example, being newly diagnosed or newly registered to the practice. ${ }^{33}$ Campbell et al found that exception reporting was mainly used at the end of the payment year to meet unmet targets and prevent the practice being penalised financially. ${ }^{31}$ Although studies have noted that QOF leads to higher reporting, it has been argued that this only benefits 'compliant' patients or those with fewer comorbidities who are less likely to be exception reported. ${ }^{21} 23$

A review by Langdown and Peckham highlighted that the use of disproportionately weighted points allows for practices to gain maximum scores without true coverage of the entire population..$^{22}$ Practices may focus on indicators they can perform better at to reach maximum scores while ignoring others despite their relevance.

Fleetcroft et al conducted a cross-sectional analysis exploring the relationship between the size of the financial incentive and expected health gain. ${ }^{17}$ They found no association and highlighted this could be demotivating as GPs were being incentivised to reach targets that did not have the highest health benefits.

Checkland and Harrison conducted a qualitative study on QOF's effect on practice organisation. ${ }^{34}$ Due to the added workload, many practices recruited additional support staff which was counterintuitive to the financial gain they received. Practices felt they were already putting in the work clinically therefore QOF had not implemented any change to practise.

\section{GP experience}

In multiple studies, GPs have expressed negative views of QOF due to impersonalisation of medicine, fragmentation of holistic care, undermining clinical leadership and an unfair distribution of finances. ${ }^{15}$

Prior to QOF, there was an uneven distribution of healthcare across the UK. QOF has since achieved a level of standardisation. Despite this, Kramer found that GPs in areas of socioeconomic deprivation struggled to meet QOF targets due to a lack of resources. ${ }^{30}$ In turn, they receive less financial compensation creating a negative cycle with even less resources to improve quality of care.

It is important to note that $\mathrm{QOF}$ indicators cover a large proportion of conditions, however, it does not cover every condition seen in general practice. Therefore, the possibility of neglecting non-incentivised conditions remains. Doran $e t$ $a l$ supported this in a longitudinal analysis to show improvements in targets attached to financial incentives at the cost of non-incentivised care. ${ }^{20}$ However, the specific study criteria biases results towards large practices, indicating more research is needed for smaller practices to analyse repeatability of the trend.

Furthermore, Norman et al found that QOF forces GPs to assess conditions using a standardised method. ${ }^{28}$ It may serve as a good baseline, however, it impinges on their ability to use specialist knowledge, tailor guidance to patients and may create pressure to diagnose and give pharmacological treatment immediately. This increases the number of unnecessary resources used therefore reducing efficiency, allocative and technical value. ${ }^{27}$

\section{Summary}

In conclusion, QOF has previously been able to create standardised care throughout primary care. However, with issues such as poor patient and GP experiences and limited evidence towards the real effect of QOF on patient health, the use of a disease-specific QOF in the future of the NHS is under question. Marshall and Roland state that 'there is little empirical evidence that QOF has a negative impact on the coordination or integration of care, provision of holistic care, or patient experience; but little sign of benefit either, ${ }^{35}$

\section{Withdrawal of QOF Indicators}

In order to identify the true effects of QOF, comparisons between performance indicators before and after the scheme's introduction have been measured. 
Minchin et al used data from over 20 million patients in 2819 English practices, and compared results against six indicators for which incentives were maintained. ${ }^{36}$ Moderate to large reductions for 12 indicators were found a year after incentive removal (ranging from 5.8\% for documentation of smoking status, to $62.3 \%$ for documentation of lifestyle counselling in patients with hypertension). When compared with expected values based on previous trends, these reductions continued for all indicators 3 years postincentive removal. However, a number of indicators are process rather than outcome measures therefore the decline in recording may not reflect worsening patient care.

Kontopantelis et al also examined the effects of withdrawal of eight indicators for patients with asthma, CHD, diabetes, stroke and psychosis. ${ }^{37}$ The study found that for the two indicators removed in April 2006, levels in 2011/2012 were very close to 2005/2006 levels. However, for five of the six indicators withdrawn from April 2011, no significant effect on performance was seen, and differences between predicted and observed scores were small. It must be highlighted that all aspects of care investigated in this study remained indirectly or partly incentivised in other areas. This study was robust due to the large nationwide sample size of 644 practices from 2004/2005 to 2011/2012 from a Clinical Practice Research Datalink of 13772992 patients.

A number of explanations behind these effects were offered, including the habituation of activities by staff and higher expectations of patients who had become accustomed to earlier experiences in clinic. Other explanations included reductions postwithdrawal being in response to updated evidence-based medicine, or due to alterations in the documentation of clinical activity in records. Incentives may increase the perceived priority of activities, and aid establishment of quality improvement infrastructures and practices.

\section{Summary}

It is difficult to establish whether the effects of QOF can be attributed to the scheme's implementation and its long-lasting effects on behaviours in primary care despite withdrawal of indicators or due to pre-2004 trends.

\section{Effects of competition as an incentive}

There were only four studies discussing the impact of competition on quality of care that met the selection criteria. Gravelle et al studied 8000 practices over 8 years and observed that increased local competition, defined as the number of rival GPs within a given radius, resulted in improved quality of care, as measured by QOF indicators and patient satisfaction. ${ }^{38}$ However, the increased number of GPs does not necessarily imply an increase in competition if there is a concomitant increase in demand due to greater population density. Furthermore, the overall effect of competition was concluded to be small in comparison to the impact of both financial and nonfinancial incentives. Negative effects of competition were also identified, with the study outlining that increased competition could lead to practices avoiding areas with existing high-quality GPs.

A study by Santos et al found similar results, with patients more likely to choose practices with higher quality. ${ }^{39}$ An increase of 10 QOF points resulted in a probability of a practice being chosen by 0.0013 . However, it was found that patients often trade-off quality for conveniently located practices. ${ }^{40}$ Despite the small increase in the probability of being chosen, it was observed that a $1 \mathrm{SD}$ increase in measured clinical quality drew in an estimated $15 \%$ more patients. However, a lack of available data comparing practices affects patient choice. ${ }^{41}$

\section{Non-financial methods of incentivising care}

Chauhan et al investigated methods of improving quality of care beyond financial incentives. ${ }^{11}$ The study was an overview of reviews which used the Behaviour Change Wheel to categorise interventions. Education, enablement (by removing barriers and creating opportunities) and persuasion (the use of communication to stimulate action) were the most effective in initiating behaviour changes in physicians. In contrast, they found financial incentives 'do not influence long-term behaviour and practice change'. ${ }^{12}$ This study highlights that behaviour change interventions are more effective in creating a sustained positive impact on patient outcomes.

Given the evidence in favour of non-financial incentives, it is unclear whether the lack of literature on this topic reflects a gap in research or an oversight in interventions that align with professional values despite evidence supporting it in other industries and countries.

\section{LIMITATIONS}

A limitation of this SLR was restriction to the UK alone as it may have benefitted from studies conducted in other countries with similar NHS-like primary care systems to provide a deeper insight. As this SLR mainly focused on medical databases, it may have missed economic based literature on policy rationale and implementation. While this review aimed to provide an overview of incentive schemes and their effectiveness, the exclusion of disease-specific studies may have led to gaps in the data, and so a more granular view may be warranted. Another limitation was that most of the literature focused on QOF as an incentive scheme and often lacked opinions from front line GPs. As this review encompassed results from other studies of differing sizes, methodology, criteria and confounding variables; the ability to draw direct conclusions is limited.

\section{CONCLUSION}

In conclusion, $\mathrm{P} 4 \mathrm{P}$ schemes are widely used throughout the NHS with QOF being the largest. The literature 
on QOF found mixed results. Positive effects such as improved chronic condition management, increased patient satisfaction and improved sociodemographic inequalities were identified. However, limitations involved decreased quality of care in non-incentivised activities, poor patient experiences due to tick-box exercises and increased pressure on practices to meet non-specific targets. The mixture of both positive and negative effects creates a lot of scrutiny for practitioners and commissioners alike.

Findings surrounding competition were mixed with limited evidence found on the use of non-financial incentives. Current research looks extensively into financial incentives, however, we propose more research into non-financial methods as drivers for quality improvement. Furthermore, research into the use of $\mathrm{P} 4 \mathrm{P}$ schemes in conjunction with non-financial schemes to improve quality of care would be valuable additions to the literature.

While this study primarily focuses on general practice in the UK, similar incentive schemes have been implemented in healthcare settings worldwide. This review can be used to help policy-makers, particularly in publicly funded healthcare systems, better understand the positive and negative consequences of incentives as quality improvement tools.

Contributors KA, SH, MK, IS, ATS and SZ contributed equally to the design, implementation, analysis of results and writing of the manuscript. AV advised and supervised the undertaking of this research project.

Funding The authors have not declared a specific grant for this research from any funding agency in the public, commercial or not-for-profit sectors.

Competing interests None declared.

Patient and public involvement Patients and/or the public were not involved in the design, or conduct, or reporting, or dissemination plans of this research.

Patient consent for publication Not required.

Provenance and peer review Not commissioned; externally peer reviewed.

Data availability statement All data relevant to the study are included in the article.

Open access This is an open access article distributed in accordance with the Creative Commons Attribution Non Commercial (CC BY-NC 4.0) license, which permits others to distribute, remix, adapt, build upon this work non-commercially, and license their derivative works on different terms, provided the original work is properly cited, appropriate credit is given, any changes made indicated, and the use is non-commercial. See: http://creativecommons.org/licenses/by-nc/4.0/.

\section{ORCID IDs}

Kanwal Ahmed http://orcid.org/0000-0002-6084-6783

Ilhan Said http://orcid.org/0000-0002-3283-3547

\section{REFERENCES}

1 World Health Organisation. Who definition of quality care, 2019. Available: https://www.who.int/maternal_child_adolescent/topics/ quality-of-care/definition/en/ [Accessed 4 May 2019].

2 Forbes L, Marchand C, Peckham S. Review of the quality and outcomes framework in England, 2016. Available: https://www. researchgate.net/publication/313444283_Review_of_the_Quality and_Outcomes_Framework_in_England [Accessed 20 Mar 2019].

3 NHS England. Report of the review of quality and outcomes framework in England, 2018. Available: https://www.england.nhs.uk/ wp-content/uploads/2018/07/quality-outcome-framework-report-ofthe-review.pdf [Accessed 20 Mar 2019].
4 Forbes LJ, Marchand C, Doran T, et al. The role of the quality and outcomes framework in the care of long-term conditions: a systematic review. Br J Gen Pract 2017;67:e784:e775-84.

5 The Health Foundation. Competition in healthcare, 2011. Available: https://www.health.org.uk/sites/default/files/CompetitionlnHea Ithcare.pdf [Accessed 20 Mar 2019].

6 Addicott R, Ham C. Commissioning and funding general practice, 2014. Available: https://www.kingsfund.org.uk/sites/default/files/field/ field_publication_file/commissioning-and-funding-general-practicekingsfund-feb14.pdf [Accessed 20 Mar 2019].

7 Flodgren G, Eccles MP, Shepperd S, et al. An overview of reviews evaluating the effectiveness of financial incentives in changing healthcare professional behaviours and patient outcomes. Cochrane Database Syst Rev 2011;6:CD009255.

8 Peckham S, Gousia K. GP payment schemes review October 2014. Centre for Health Services Studies, University of Kent, 2014.

9 Witter S, Toonen J, Meessen B, et al. Performance-based financing as a health system reform: mapping the key dimensions for monitoring and evaluation. BMC Health Serv Res 2013;13:367.

10 Scott A, Sivey P, Ait Ouakrim D, et al. The effect of financial incentives on the quality of health care provided by primary care physicians. Cochrane Database Syst Rev 2011;168:CD008451.

11 Chauhan BF, Jeyaraman MM, Mann AS, et al. Behavior change interventions and policies influencing primary healthcare professionals' practice-an overview of reviews. Implement Sci 2017;12:3.

12 Michie S, van Stralen MM, West R. The behaviour change wheel: a new method for characterising and designing behaviour change interventions. Implement Sci 2011;6:42.

13 Allen T, Whittaker W, Kontopantelis E, et al. Influence of financial and reputational incentives on primary care performance: a longitudinal study. Br J Gen Pract 2018;68:e811-8.

14 Hackett J, Glidewell L, West R, et al. 'Just another incentive scheme': a qualitative interview study of a local pay-for-performance scheme for primary care. BMC Fam Pract 2014;15:168.

15 Roland M, Campbell S. Successes and failures of pay for performance in the United Kingdom. N Engl J Med 2014;370:1944-9.

16 Raleigh V, Frosini F. Improving GP services in England: exploring the association between quality of care and the experience of patients, 2012. Available: https://www.kingsfund.org.uk/sites/default/files/ field/field publication file/improving-gp-services-in-england-thekings-fund-nov-2012.pdf [Accessed 22 Mar 2019].

17 Fleetcroft R, Parekh-Bhurke S, Howe A, et al. The UK pay-forperformance programme in primary care: estimation of population mortality reduction. Br J Gen Pract 2010;60:e345-52.

18 Kontopantelis E, Springate DA, Ashworth M, et al. Investigating the relationship between quality of primary care and premature mortality in England: a spatial whole-population study. BMJ 2015;350:h904.

19 Fleetcroft R, Steel N, Cookson R, et al. Incentive payments are not related to expected health gain in the pay for performance scheme for UK primary care: cross-sectional analysis. BMC Health Serv Res 2012;12:94.

20 Doran T, Kontopantelis E, Valderas JM, et al. Effect of financial incentives on incentivised and non-incentivised clinical activities: longitudinal analysis of data from the UK quality and outcomes framework. BMJ 2011;342:d3590.

21 Mandavia R, Mehta N, Schilder A, et al. Effectiveness of UK provider financial incentives on quality of care: a systematic review. $\mathrm{Br} J \mathrm{Gen}$ Pract 2017;67:e800-15.

22 Langdown C, Peckham S. The use of financial incentives to help improve health outcomes: is the quality and outcomes framework fit for purpose? A systematic review. J Public Health 2014;36:251-8.

23 Dixon A, Khachatryan A, Wallace A. The quality and outcomes framework (QOF): does it reduce health inequalities? National Institute for health research, 2011. Available: http://www.netscc.ac. uk/hsdr/files/project/SDO_FR_08-1716-207_V01.pdf [Accessed 20 March 2011].

24 Gillam SJ, Siriwardena AN, Steel N. Pay-For-Performance in the United Kingdom: impact of the quality and outcomes framework: a systematic review. Ann Fam Med 2012;10:461-8.

25 Ashworth M, Kordowicz M. Quality and outcomes framework: smoke and mirrors? quality in primary care, 2010. Available: http://www. ingentaconnect.com/content/rmp/qpc/2010/00000018/00000002/ art00007 [Accessed 17 May 2019].

26 Fichera E, Pezzino M. Pay for performance and contractual choice: the case of general practitioners in England. Health Econ Rev 2017;7:1-14.

27 Cripps M. Nhs right care, 2016. Available: https://www.england.nhs. uk/rightcare/2016/10/07/matthew-cripps/ [Accessed 17 May 2019]. 
28 Norman AH, Russell AJ, Macnaughton J. The payment for performance model and its influence on British general practitioners' principles and practice. Cad. Saúde Pública 2014;30:55-67.

29 Chew-Graham CA, Hunter C, Langer S, et al. How QOF is shaping primary care review consultations: a longitudinal qualitative study. BMC Fam Pract 2013;14:103.

30 Kramer G. Payment for performance and the QOF: are we doing the right thing? Br J Gen Pract 2012;62:e217-9.

31 Campbell SM, Reeves D, Kontopantelis E, et al. Effects of pay for performance on the quality of primary care in England. $N$ Engl $J$ Med 2009;361:368-78.

32 Adamou M, Hale AS. Total quality management in the NHS in England and Wales: a story untold? Journal of quality health care 2004. Available: http://eprints.hud.ac.uk/11324/ [Accessed 22 May 2019].

33 NHS Digital. Exception reporting definition, 2018. Available: https:// digital.nhs.uk/data-and-information/publications/statistical/qualityand-outcomes-framework-exception-data/quality-and-outcomesframework-2009-10-exception-reporting [Accessed 11 May19].

34 Checkland K, Harrison S. The impact of the quality and outcomes framework on practice organisation and service delivery: summary of evidence from two qualitative studies. quality in primary care, 2010.
Available: http://www.ingentaconnect.com/content/rmp/qpc/2010/ 00000018/00000002/art00009 [Accessed 20 Mar 2019].

35 Marshall M, Roland M. The future of the quality and outcomes framework in England. BMJ 2017;359:j4681.

36 Minchin M, Roland M, Richardson J, et al. Quality of care in the United Kingdom after removal of financial incentives. N Engl J Med Overseas Ed 2018;379:948-57.

37 Kontopantelis E, Springate D, Reeves D, et al. Withdrawing performance indicators: retrospective analysis of general practice performance under UK quality and outcomes framework. BMJ 2014;348:9330.

38 Gravelle H, Liu D, Propper C. Spatial competition and quality: evidence from the English family doctor market. Centre for Health Economics, University of York, 2018.

39 Santos R, Gravelle H, Propper C. Does quality affect patients' choice of doctor? Evidence from England. Econ J 2017;127:445-94.

40 Mays N, Eastmure E, Erens B. Evaluation of the choice of GP practice pilot, 2012-13. Available: http://researchonline.Ishtm.ac.uk/ 2478759/ [Accessed 27 Mar 2017].

41 Featherstone $\mathrm{H}$, Storey $\mathrm{C}$. Which doctor? putting patients in charge of primary care, 2009. Available: https://www.policyexchange.org.uk/ wp-content/uploads/2016/09/which-doctor-dec-09.pdf [Accessed 27 Mar 2019]. 